\title{
LA COOPERACIÓN TRANSFRONTERIZA EN LA CERDANYA (FRONTERA ESPAÑA-FRANCIA)
}

\author{
Xavier Oliveras González \\ Departament de Geografia, Universitat Autònoma de Barcelona \\ xavier.oliveras@uab.cat
}

\section{RESUMEN}

La cooperación transfronteriza en la frontera hispano-francesa se inicia en la década de 1980, consolidando varios espacios locales y comarcales transfronterizos, como la Cerdanya. En este espacio se han constituido algunos organismos transfronterizos, a la par que se han desarrollado proyectos en varios ámbitos sectoriales, como la gestión del agua, la sanidad, la enseñanza y la ganadería. Su análisis permite identificar diferencias territoriales, estrategias de implementación, motivaciones y obstáculos (administrativas, jurídicas, técnicas y políticas).

Palabras clave: cooperación transfronteriza, región transfronteriza, Cerdanya.

\begin{abstract}
Cross-border cooperation in the Spanish-French border began in 1980's. Its development consolidated several local cross-border areas, including Cerdanya. In this space some cross-border bodies have been created and various projects have been developed in various thematic areas such as water management, health, education and livestock farming. The analysis drives to the identification of some territorial differences, implementation strategies, motivations and obstacles (administrative, legal, technical and political).
\end{abstract}

Key words: cross-border cooperation, cross-border region, Cerdanya.

Fecha de recepción: julio 2011.

Fecha de aceptación: enero 2013. 


\section{INTRODUCCIÓN}

El Himno de la Cerdanya, compuesto por el autor de la Renaixença Francesc Matheu (1851-1938), canta «Meitat d'Espanya, meitat de França, no hi ha altra terra com la Cerdanya», que sintetiza el carácter transfronterizo de esta comarca: su división entre los estados español y francés, y su unidad a pesar de ello. La frontera entre ambos estados, establecida en 1659-1660 por el Tratado de los Pirineos y ratificada por el Tratado de Límites de 1866, dividió un territorio con una precedente unidad política, social y cultural, además de geomorfológica en el seno de los Pirineos. Desde el momento de su división, se movilizaron estrategias socioeconómicas, socioculturales, políticoadministrativas y territoriales divergentes en cada uno de los lados, que progresivamente provocaron diferencias relativas a las infraestructuras de transporte, sistemas educativo y sanitario, comercio, estilos arquitectónicos, legislación, simbología, lengua, ritmos temporales, entre otros (Sahlins, 1993; Moncusí, 2005 y 2008; Jané, 2006 y 2009; Brunet, 2008).

Como se tratará de mostrar, la frontera y las diferencias no han impedido las interrelaciones, sino que por el contrario la Cerdanya se ha constituido como una «región transfronteriza». La presente investigación se apoya en la aproximación teórica de la construcción de regiones transfronterizas (Hamman, 2003; Perkmann, 2003; Hinfray, 2007; Leloup, 2010; Oliveras, Durà y Perkmann, 2010; Trillo y Lois, 2011; entre muchos otros), derivada de la perspectiva de la «nueva geografía regional». A nivel teórico existen variadas opiniones sobre la naturaleza, características, origen, funciones o límites de las regiones transfronterizas, pero en síntesis se puede argumentar que son el resultado de un proceso de construcción en el que confluyen los siguientes seis elementos:

a) territorio: dividido por una frontera política (con sus consiguientes efectos), pero a pesar de ello con procesos territoriales similares e intraconectado.

b) dinámicas transfronterizas: de carácter social (relaciones familiares o de amistad, movilidad sanitaria, entre otras), económico (movilidad laboral, flujos comerciales o sinergias y economías de escala, etc.) o ambiental (flujos de agua, de energía, de fauna, etc.).

c) agentes territoriales: públicos o privados, con capacidad de movilizar recursos y poner en marcha proyectos de interés mutuo.

d) proyecto: político, de desarrollo económico, empresarial, de servicios públicos, de gestión del territorio, etc., de interés mutuo, materializado por medio de procesos de cooperación.

e) identidad: común, basada en una cultura, una lengua, unos símbolos, una historia o un territorio compartidos.

f) discursos y narrativas transfronterizas: de unidad geográfica, histórica, socioeconómica y/o sociocultural y de continuidad práctica, que proyecten la idea de compartir un territorio, unas dinámicas, unos proyectos y/o una identidad.

En este marco, la cooperación transfronteriza, es decir, la colaboración más o menos institucionalizada entre autoridades y/o entidades subestatales colindantes de dos o más estados y orientada a la coordinación de políticas y acciones, constituye una de las estrategias para la construcción de regiones transfronterizas. 
El análisis de la Cerdanya como región transfronteriza se ha centrado en los aspectos económicos, culturales y sociales (Fornier, 1969; Tulla, 1977 y 1997; Mancebo, 1999a y 2000; Moncusí, 2005 y 2008; MOT y UdG, 2008; Quílez, 2009; Spa, 2011, entre otros). En cambio la cooperación transfronteriza ha recibido una menor atención y ha priorizado el principio temático por encima del regional: en materia de museos (Mancebo, 1999b; Mercadal y Iniesta; 1999; Harguindéguy, 2007), sanidad (Séchet y Keerle, 2009 y 2010) y agua (Mancebo, 2000; Maury y Richard, 2011; Oliveras, 2012). A menudo han prevalido, no sin razón, los argumentos funcionalistas y economicistas, dejando en segundo término otras explicaciones, como la cultural. En este sentido, como se verá, varios elementos han tenido un papel central en el desarrollo de la cooperación, pero también de su ausencia: una identidad territorial y cultural móvil, a veces cerdana y catalana, pero cuando conviene también española y francesa; la persistencia, desaparición o instrumentalización de la frontera en función de los intereses, en tanto que configurada como una «frontera a la carta» (Mancebo, 1999b) o en una «nacionalización del interés» (Sahlins, 1993); y la construcción del discurso de la «Cerdanya unida», argumentado sobre criterios históricos, naturales y culturales, a menudo idealizados. Estos tres elementos se han utilizado simultáneamente, en un sistema retroalimentado, como justificación y fin de la cooperación. En el conjunto de la frontera hispano-francesa, una situación pareja se da en el valle de Baigorri y el País Quinto, en el Pirineo occidental (Dornel, 2002; Murray, 2003).

El presente artículo pretende discutir algunas de las opiniones sobre las características de la cooperación en la Cerdanya y aportar una visión más global sobre este fenómeno en el marco de su construcción cómo región transfronteriza. En primer lugar se detallará el marco general de la cooperación en la frontera España-Francia. A continuación se expondrá su implementación concreta en la Cerdanya y, por último, se analizarán en mayor detalle cuatro sectores representativos: la gestión del agua, sanidad, enseñanza y ganadería y alimentación.

\section{EL MARCO DE LA COOPERACIÓN TRANSFRONTERIZA EN LA FRONTERA ESPAÑA-FRANCIA}

La moderna cooperación transfronteriza en Europa se inicia en los años 1950-60 en las fronteras de la Europa occidental y nórdica. Lenta pero progresivamente se implantó en el resto de fronteras, hasta cubrir actualmente la práctica totalidad del continente. En la frontera España-Francia se desarrolla a partir de 1980 (sin contar los hermanamientos entre municipios, que se establecen antes) y su estado actual tiene ya una cierta importancia, por su densidad, diversidad y perdurabilidad. Paralelamente a su desarrollo, ha sido tratado en varios estudios, de los que cabe destacar los de Fernández de Casadavante (1989 y 1990), Fernández y Peralta (1994), Muñoz (1995), Tambou (2000), Arbaiza (2006) o Harguindéguy (2007), entre otros.

En la frontera hispano-francesa, el Consejo de Europa (CdE) había propuesto en 1971 la creación de un organismo «aquitano-cantábrico» en su sector occidental, que nunca llegó a ponerse en práctica. No fue hasta 1983, con la fundación de la Comunidad de Trabajo de los Pirineos $(\mathrm{CTP})^{1}$ a instancias del mismo, que se da inicio a la cooperación transfronteriza.

1 La CTP agrupa Aragón, Catalunya, Navarra, Euskadi, Languedoc-Roussillon, Midi-Pyrénées, Aquitaine y Andorra. 
Desde entonces se han establecido varios organismos y proyectos de cooperación, desde la escala regional hasta la local. Puede hacerse referencia a la Euroregión Pirienos-Mediterráneo y al Eurodistrito del Espacio Catalán Transfronterizo, en el sector oriental de la frontera, o la Eurorregión Aquitania-Euskadi y la Eurociudad Vasca Bayona-San Sebastián, en el oriental $^{2}$, entre otros.

Con anterioridad a la moderna cooperación se dieron numerosas formas de colaboración local, que constituyen claros antecedentes (de hecho, algunas iniciativas actuales se justifican en ellos). Destacan los llamados «Tratados de Alianza y Facerías», acuerdos entre comunidades locales que se remontan a la Edad Media, referentes al uso de pastos, bosques, aguas o caminos transfronterizos, comercio y ayuda mutua, incluso en tiempos de guerra entre los dos países. Estas colaboraciones se mantienen hasta la construcción de los modernos estados liberales, incluyendo la definitiva delimitación, fijación y consolidación de la frontera con los Tratados de Limites (o Tratados de Bayona) de 1856, 1862 y $1866^{3}$. Con ello se pasaba a controlar (aparentemente) cualquier actividad transfronteriza, limitando hasta su casi extinción los «Tratados de Alianza y Facerías». El periodo 1850-1980 se caracteriza por la limitación legal de las relaciones, el dominio de los agentes de nivel estatal y, por el contrario, la ausencia formal de los niveles regional y local. Las colaboraciones se vieron muy mermadas también a lo largo del siglo XX por la crisis de las actividades agrarias tradicionales, sobre las que muchas se apoyaban (Muñoz, 1995; Moncusí, 2008). Sin embargo, una encuesta realizada en 1982 a 163 autoridades locales de ambos lados de la frontera mostraba que se habían mantenido algunas relaciones institucionales, de forma no sistemática, informalmente y de poca intensidad (Bernad, 1984; Fernández y Peralta, 1994).

Con base en los Tratados de Límites se creó en 1875 la Comisión Internacional de los Pirineos (CIP), que durante más de un siglo ha sido el único organismo transfronterizo entre España y Francia, y hoy constituye la más antigua comisión interestatal fronteriza permanente de Europa. Sus facultades son el estudio, propuesta y recomendación en una amplia variedad de cuestiones (agricultura, medio ambiente, aguas, infraestructuras de transporte, energía, incendios, socorro, etc.), además de la intermediación en caso de disputas fronterizas. Inicialmente estuvo integrada por cargos estatales (diplomáticos, ministros, militares o funcionarios de aduanas), aunque progresivamente los agentes locales y regionales supieron encontrar mecanismos de participación más o menos formal.

La plena integración en el marco institucional europeo (el ingreso de España en la CEE en 1986, la apertura de la frontera con el Acuerdo de Schengen de 1995 o el uso del euro desde 2002) es la clave para entender la implantación de la moderna cooperación transfronteriza. A esto cabe añadir los cambios que, a partir de los años 1970, se producen a nivel supraestatal y estatal y que conducen en los 80 a su desarrollo. Los factores principales son tres.

2 La Euroregión Pirienos-Mediterráneo agrupa Baleares, Catalunya, Languedoc-Roussillon y Midi-Pyrénées; el Eurodistrito del Espacio Catalán Transfronterizo, las Comarcas de Girona y el departamento de PyrénéesOrientales; la Eurorregión Aquitania-Euskadi, estas dos regiones; y la Eurociudad Vasca, Guipuzkoa y el distrito Bayonne-Anglet-Biarritz (en el departamento de Pyrénées-Atlantiques).

3 Sobre el trazado y demarcación de esta frontera pueden verse desde los clásicos trabajos de Cordero (1960) y Sermet (1983) hasta el más reciente de Capdevila (2009). 
En primer lugar, la descentralización de España y Francia, entre fines de los años 70 y a lo largo de los 80, se acompañó de la dotación de autonomía política y financiera a sus entidades subestatales (municipios, departamentos y provincias, y regiones, y sus agrupaciones), aunque con una distribución competencial más amplia en el primero que en el segundo. Esta autonomía facilitó el establecimiento de acuerdos de cooperación transfronteriza, aunque no fue hasta 1992, en el caso francés, y 1997 en el español, que los estados legislaron en este sentido. Ambas legislaciones son similares: obligan a una comunicación previa a la administración central, una restricción dentro de los límites competenciales y el respeto a los compromisos internacionales del estado. Asimismo definen la personalidad jurídica de los organismos de cooperación (Groupements d'Intérêt Public, Sociétés d'Économie Mixte Locales y Districts Européens, y Consorcios). Debe añadirse también la creación de organismos estatales de apoyo a la cooperación transfronteriza, por ahora sólo en Francia. Tal es el caso de la Mission Opérationelle Transfrontalière (MOT), creada en 1997, que da servicio al estado y a sus colectividades territoriales fronterizas, además de aquéllas pertenecientes a estados fronterizos que estén adheridas (en el caso español, la Generalitat de Catalunya y la Diputación Foral de Guipuzkoa).

En segundo lugar, en 1980 el CdE aprobó el Convenio-marco europeo de cooperación transfronteriza entre autoridades y comunidades territoriales (o Convenio-marco de Madrid), la primera regulación jurídica de sus características, y ampliado posteriormente con tres protocolos adicionales (en 1995, 1998 y 2009). España y Francia lo ratificaron en 1990 y 1984, seguido en 1995 de la rúbrica de un acuerdo bilateral, el Tratado relativo a la cooperación transfronteriza entre colectividades territoriales (o Tratado de Bayona). Por este tratado se autoriza a las respectivas entidades subestatales fronterizas ${ }^{4}$ a establecer convenios de cooperación y constituir organismos ( sin o con personalidad jurídica de derecho público), con los objetivos de crear y gestionar equipamientos y servicios públicos, estudiar y coordinar decisiones en los dominios de interés común y formular propuestas de cooperación. A fines de 2010 se habían firmado 33 convenios $^{5}$, tales como el Consorcio Transfronterizo Bidasoa-Txingudi (1999), el Convenio de cooperación entre Aragón y Midi-Pyrénées (2001), la Plataforma Logística de Aquitaine-Euskadi (2003) o la CTP, que se adaptó en 2005. Asimismo, ambos estados han firmado otros acuerdos bilaterales sectoriales donde, de acuerdo al Tratado de Bayona, se contempla la cooperación, tales como el Acuerdo de Toulouse de 2006 sobre cuencas hidrográficas transfronterizas o, muy especialmente, el Acuerdo marco sobre cooperación sanitaria transfronteriza de 2008. Este último, por ejemplo, tiene por objeto mejorar el acceso a la asistencia sanitaria, garantizar su continuidad entre las poblaciones de la zona fronteriza y simplificar los procedimientos administrativos y financieros. Refleja el interés y las necesidades de la cooperación en este ámbito, caracterizado por la

4 Las regiones españolas incluidas son Aragón, Catalunya, Euskadi y Navarra (y sus provincias y municipios, y sus agrupaciones); las francesas son Aquitaine, Languedoc-Roussillon, Midi-Pyrénées (y sus departamentos y municipios, y sus agrupaciones). En julio de 2012 se adherió Andorra, a pesar que todavía no había firmado ni ratificado el Convenio-marco de Madrid.

5 En: La cooperación transfronteriza realizada por las entidades territoriales españolas (noviembre 2010), Ministerio de Política Territorial y Administración Pública.

http://www.mpt.gob.es/areas/politica_autonomica/coop_multilateral_ccaa_ue/Menu_Coop_TransfrCooperacion/Coop_Transfronteriza.html. 
variedad de especialidades concertadas, esencialmente en el litoral vasco (entre Biarritz y Donosti) y el tramo catalán de la frontera.

En 2006 la UE creó su propia regulación jurídica, el Reglamento sobre las Agrupaciones Europeas de Cooperación Territorial (AECT), que supera algunas de las limitaciones del Convenio-marco de Madrid. Tres años después España y Francia acordaron el procedimiento de participación de sus entidades subestatales, y a fines de 2011 ya eran 12 las AECTs aprobadas o en tramitación ${ }^{6}$, entre las que se cuentan la Euroregión Pirineos-Mediterráneo o el Espacio Portalet. Con anterioridad se había extendido el uso de otro reglamento de la UE, el de las Agrupaciones Económicas de Interés Europeo (AEIE), como figura jurídica de facto, tal y como había hecho la Red de Ciudades C-6.

En tercer y último lugar, en 1989 la UE puso en marcha los programas INTERREG para la financiación de proyectos de cooperación transfronteriza. Para la frontera hispanofrancesa se ha canalizado mediante el programa operacional INTERREG Francia-España Pirineos y, a partir de la reforma de 2007, Cooperación Transfronteriza España-FranciaAndorra (POCTEFA). En los primeros años su gestión fue monopolizada por los estados, por lo que dicho programa se utilizó en gran medida para financiar proyectos que no tenían un claro objetivo transfronterizo. Sólo tardíamente se integraron las entidades subestatales, designándose en 2007 la CTP como «autoridad de gestión», con lo que se espera una mayor rigurosidad (Heredero y Olmedillas, 2009; Harguindéguy y Rodríguez, 2010). Al igual que el conjunto de programas operacionales en el resto de Europa, su dotación presupuestaria se ha incrementado progresivamente: 31'2 M€ (I, 1990-1993), 63 M€ (II, 1994-1999), 86'17 M€ (III, 2000-2006), hasta los actuales 168,64 M€ (IV o Cooperación Territorial Europea, 2007-2013).

\section{EL MARCO DE LA COOPERACIÓN TRANSFRONTERIZA EN LA CERDANYA}

La Cerdanya (Baixa Cerdanya, Alta Cerdanya y Capcir) ${ }^{7}$ (figura 1) contaba en 2008 con una población de iure de 33.725 habitantes, de los que un 55\% se situaba en el lado español y un $45 \%$ en el francés. Desde los años 1980 el sector turístico, y los servicios en general, ha constituido el pilar básico de su economía (el 70\% de la población activa entre 2001 y 2008), junto con la construcción (21\%), en detrimento de las actividades agrarias (5\%), mientras que las industriales $(9 \%$ ) nunca han sido muy importantes (a excepción de Puigcerdà y Saillagouse). Se calcula que en 2005 la población ascendía hasta 150.000 habitantes durante los picos turísticos (vacaciones de invierno y verano, y fines de semana). La especialización

6 En: Agrupaciones Europeas de Cooperación Territorial en España (octubre 2011), Ministerio de Política Territorial y Administración Pública.

http://www.mpt.gob.es/areas/politica_autonomica/coop_multilateral_ccaa_ue/Menu_Coop_TransfrCooperacion/AECT.html.

7 En el estado español: la Baixa Cerdanya, corresponde a la comarca de la Cerdanya (divida entre las provincias de Girona y Lleida), cuyo órgano político-administrativo es el Consell Comarcal de la Cerdanya. En el estado francés, la Alta Cerdanya y Capcir corresponden a los cantones de Saillagouse y, parcialmente, Mont-Louis (departamento de Pyrénées-Orientales), que no disponen de órgano político-administrativo, pero cuyos municipios (comunas) se organizan en varios «établissements publics de coopération locale»: Communauté de communes Pyrénées-Cerdagne, Communauté de communes Capcir-Haut Conflent, Syndicat intercommunal de la Haute Cerdagne, Syndicat mixte de la Haute vallée du Segre... 
turística se ha complementado con el sector inmobiliario, que ha tenido un claro dominio por parte de los promotores españoles en ambos lados. Por otra parte, la ciudad de Puigcerdà, que constituye el principal núcleo de población (9.365 hab.), ejerce desde la década de 1970 una creciente atracción (en servicios y puestos de trabajo) sobre los pueblos de ambos lados de la frontera, y junto con Bourg-Madame (1.244 hab.) forma un continuo urbano transfronterizo que domina los principales flujos y el centro geográfico.

Figura 1

MAPAADMINISTRATIVO DE LA CERDANYA

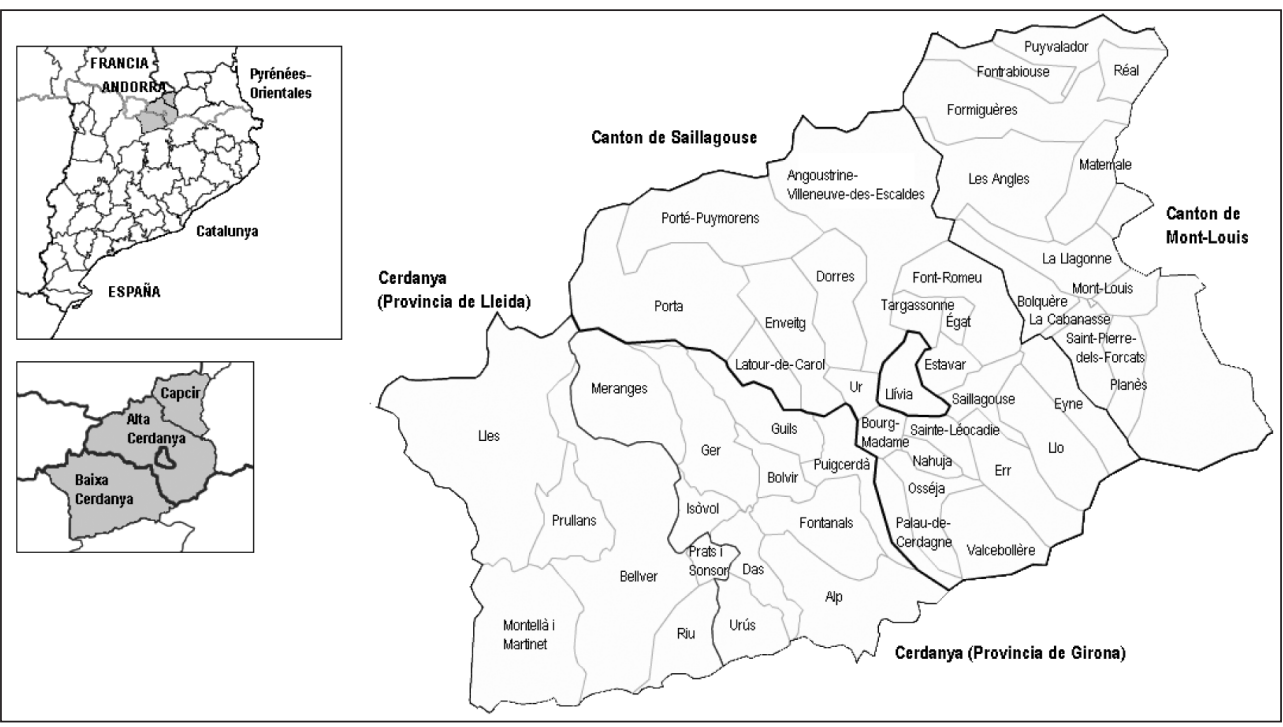

Fuente: Elaboración propia.

Ya durante las décadas de 1880 a 1930 alcaldes de un lado y otro de la frontera convocaron ocasionalmente asambleas y comisiones transfronterizas para tratar cuestiones de interés mutuo, tales como el ferrocarril transpirenaico o, como se verá más adelante, el desvío de las aguas del lago Lanoux. Después de la ruptura que supuso el franquismo, la voluntad de cooperar no volvió a plantearse hasta fines de los años 1970, materializándose una década después. Los inicios fueron complicados, a pesar de la existencia de unas tradicionales colaboraciones informales que, por otra parte, se estaban perdiendo. Importantes obstáculos y desencuentros dificultaron y retrasaron la definición de objetivos, coordinar las divergentes iniciativas, ejecutar los proyectos o establecer una estructura común de gestión. Hasta los años 90 la intensidad de proyectos fue menor a la dada en otros puntos de la frontera entre la provincia de Girona y el departamento de Pyrénées-Orientales (Muñoz, 1995), pero una vez superadas las dificultades la Cerdanya ha concentrado la mayor parte de los proyectos (MOT y UdG, 2008; Castañer, Feliu y Gutiérrez, 2011).

Las iniciativas de cooperación no se reducen a un simple carácter pecuniario ni a una exclusiva voluntad de las autoridades de Puigcerdà por capitalizar y centralizar los procesos 
territoriales, como se ha afirmado en ocasiones (Mancebo, 1999a y 2000; Harguindéguy, 2007), sino que se deben también a otras motivaciones y liderazgos. Junto a los factores generales ya expuestos, su desarrollo se explica por una capacitación local de experiencia y adaptación, una progresiva integración económica y urbana, y el rol determinante en los primeros años de las entidades culturales. Estas entidades, creadas a fines de los años 1970 como respuesta a la pérdida de las relaciones transfronterizas tradicionales, se convirtieron en un punto de encuentro de intelectuales y agentes económicos de ambos lados, aunque su implantación fue desigual, con una mayor presencia en el lado español. Sus objetivos respondían a la voluntad de pensar la Cerdanya en conjunto, basándose en una realidad natural, cultural e histórica que justificara su unidad y, consiguientemente, prescindiera y superara la frontera internacional. Las más activas fueron el «Institut d'Estudis Ceretans» (IEC, con sede en Puigcerdà y Enveitg) y las asociaciones que pusieron en marcha publicaciones periódicas de información general, como «Amics de Cerdanya» de Puigcerdà (Rufaca) o «Le Petit Cerdan» de Palau-de-Cerdagne ( L'Aixurit). Actualmente el liderazgo que ejercían lo han perdido (de hecho, sólo el IEC continúa en activo), en detrimento de los gobiernos locales.

A iniciativa originalmente del IEC se celebra desde 1981 la Diada de la Cerdanya, que busca afianzar dicha unidad, su catalanidad y negar la frontera, y en la que participan ayuntamientos, asociaciones locales y población en general. Los actos se celebran cada año en un municipio diferente y, aunque resulte paradójico, alternativamente a un lado y otro de la frontera (figura 2). La Diada incluye varios actos, unos de carácter lúdicofestivo y otros de político. En este segundo sentido, la festividad se ha convertido en el lugar de encuentro de los diferentes municipios, hasta el punto que desde 1998 coincide con un oficial «encuentro anual de alcaldes». Durante la parte política se (re)producen declaraciones sobre la unidad de la Cerdanya, que desde 2009 es presidida por una bandera propia. Se suele acompañar, además, de la creación de símbolos en el paisaje urbano que atestigüen la unidad, tales como las inauguraciones del «carrer de Cerdanya» en Llo (1982) o de la «placeta de Cerdanya» en Bourg-Madame (1985), en cuya construcción se emplearon materiales procedentes de ambos lados. En 1989, con el inicio de INTERREG, los alcaldes mostraron un claro interés por la cooperación transfronteriza y la Diada se convierte en el espacio para la proposición y debate de proyectos y su posible financiación. A lo largo de los años se ha tratado la cooperación en varios campos: gestión forestal y prevención de incendios, sanidad, infraestructuras de transporte, promoción turística, gestión del agua, cultura, educación, etc.

En 1984, en vistas de la integración de España en la CEE, se propuso establecer una estructura permanente de concertación que agrupara todos los municipios. La iniciativa partió de los alcaldes de Bourg-Madame, Joseph Calvet, y de Puigcerdà, Joan Llombart, y del diputado en el Parlament de Catalunya y antiguo alcalde de Puigcerdà Josep Moliner. No llegó a crearse, pero fue la ocasión para repensar algunos proyectos en una escala comarcal redimensionada. Por citar un ejemplo, el polígono industrial Sector Estació, en Puigcerdà, se amplió de 8 a 22 hectáreas teniendo en cuenta este nuevo espacio.

La creación de un organismo tal se puso de nuevo sobre la mesa poco después, en el marco de la Diada de 1989 (en Llívia). La propuesta, formulada por los alcaldes de FontRomeu-Odeillo-Via, Pierre Bosselut, y Osséja, Paul Souliné, y el presidente del Consell Comarcal de la Cerdanya y alcalde de Alp, Josep Tajà, partía de la identificación de unos problemas y unos medios comunes de desarrollo económico. Con la ayuda del Patronat Català 
Pro Europa, en 1991 se constituyó formalmente la Asociación de Municipios de la Cerdanya (AMC), donde se integraron la mayoría de los municipios (43 de los 50), incluido el Consell Comarcal de la Cerdanya. El objetivo principal consistía en restituir la unidad comarcal y desarrollar una colaboración permanente, especialmente en relación con el medio ambiente (aguas residuales y residuos sólidos), infraestructuras de transporte, sanidad, cultura y promoción turística. Entre los principales proyectos planteados se cuentan varios equipamientos de uso y gestión compartida: la construcción de una depuradora en Puigcerdà, la conversión del aeródromo de Alp en aeropuerto, la construcción de un vertedero entre Saillagouse y Llo y la creación de un Archivo en Puigcerdà. Sin embargo, la falta de financiación europea y unas expectativas demasiado altas condujeron a una creciente frustración y finalmente a su disolución poco tiempo después.

En 1998, y de nuevo en el marco de la Diada, los alcaldes presentes acordaron y firmaron el Manifiesto de Font-Romeu, que es ratificado ritualmente en las siguientes diadas. Su redacción fue promovida básicamente por el IEC y obtuvo una amplia aceptación. Partiendo de la experiencia de la AMC (éxitos, fracasos y carencias), en él se reclama el reconocimiento de la Cerdanya como unidad histórica, cultural y socioeconómica en el marco de la Europa integrada, la creación de un ente gestor para la planificación y el desarrollo de todo el territorio y la creación de un Consejo General de la Cerdanya que reuniera (¿y sustituyera?) al Consell Comarcal de la Cerdanya y la Communauté de Communes Pyrénées Cerdagne.

En posteriores encuentros de alcaldes se debatieron los criterios de creación de dicho Consejo General, pero no fue hasta la Diada de 2008 (en Isòvol) que se acordó emprender su creación, aprovechando el Reglamento de las AECT. Después de un largo proceso de tramitación, a principios de 2012 se constituyó la AECT Pirineus-Cerdanya, con sede en Saillagouse (figura 2). Este organismo está formado por las dos administraciones comarcales antes mencionadas, y está abierto a la participación de todos los municipios de la Alta Cerdanya no integrados en la Communauté de Communes, de Capcir, Ariège, Berguedà y Alt Urgell. Sus objetivos se centran en los ámbitos de la planificación territorial, las infraestructuras de transporte, la lengua y cultura catalanas, y la economía y el turismo. Las primeras acciones desarrolladas corresponden justamente a este último ámbito: la edición de una guía de senderos y la organización de una carrera de ultrafondo siguiendo la «Gran Volta a la Cerdanya», un sendero de $215 \mathrm{Km}$ que recorre todo el valle.

En los núcleos más estrictamente transfronterizos, Puigcerdà-Bourg-Madame y LlíviaEstavar, la planificación de proyectos de cooperación se inicia también en 1989. A propuesta y liderazgo de Llívia se constituyó una estructura de concertación con Estavar, por que la mostraron interés en adherirse Angoustrine-Villeneuve-des-Escaldes, Sainte-Léocadie y BourgMadame. Se formalizó en 1991 con la firma de la Carta de cooperación y el establecimiento de la «Conferencia de Consejos Municipales». La cooperación se desarrolló en el campo de la cultura, el deporte y el urbanismo, con la co-organización del «Festival de Vídeo Estavar-Llívia» (entre 1990 y 2001) y de la competición atlética «Cursa de l'Enclavament», la construcción de un polideportivo (el «Fòrum de Llívia», inaugurado en 1999) y la urbanización de una avenida uniendo ambos núcleos (la Avinguda dels Països Catalans). Para todos los proyectos se solicitó financiación europea, pero solamente se obtuvo para el polideportivo.

La colaboración entre Puigcerdà y Bourg-Madame, por otra parte, se diferencia de las anteriores en legitimarse por la continuidad urbana y no tanto por aspectos identitarios. Des- 
pués de ciertos impedimentos por parte de las autoridades centrales francesas, en 1995 se firmó un convenio con el objeto de identificar y aportar soluciones a problemáticas comunes (residuos urbanos, atención sanitaria, telecomunicaciones, máquinas quitanieve, etc.). La progresiva intensificación condujo en 2002 a la constitución de un Consorcio transfronterizo, sobre la base del Tratado de Bayona, que permitió obtener mayor cobertura jurídica y financiera. Sus campos de actuación son varios: promoción turística, urbanismo, sanidad, educación, cultura, medio ambiente y desarrollo económico. Entre los resultados se pueden mencionar la revisión de vehículos comerciales e industriales de la Alta Cerdanya y Capcir en la estación ITV de Puigcerdà, el servicio compartido de recogida de basuras o el proyecto urbanístico «Matrimoni sense frontera» para la reordenación de la Avenue Porte de France y la Avinguda del Segre, incluido el puente internacional sobre el río Raür, que enlazan ambas localidades. Como en el anterior caso, otros municipios de la Alta Cerdanya mostraron interés en sumarse (Palau-de-Cerdagne, Estavar, Font-Romeu-Odeillo-Via y Latour-de-Carol). A pesar del entusiasmo de unos, también se generaron ciertos rechazos, sobre todo en el lado francés: para algunos se trataba más de una «incorporación» de Bourg-Madame a Puigcerdà que no una «cooperación equilibrada».

\section{ALGUNOS EJEMPLOS}

En el punto anterior ya se han apuntado los principales sectores objeto de cooperación, que, de acuerdo al Tratado de Bayona, se ajustan a las competencias municipales y regio-

\section{LA COOPERACIÓN TRANSFRONTERIZA EN LA CERDANYA}

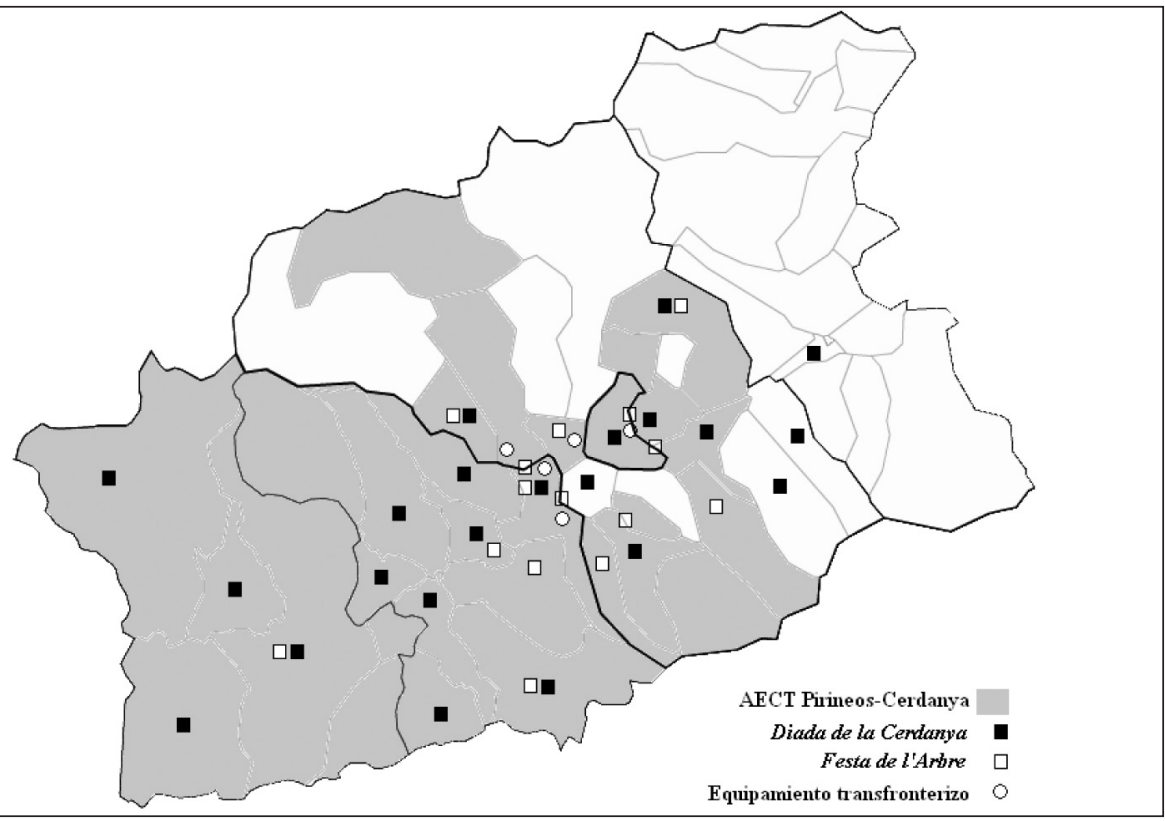

Fuente: Elaboración propia 
nales: turismo, deporte, educación, urbanismo, medio ambiente, cultura, servicios sociales, planificación territorial, infraestructuras de transporte y desarrollo económico. De estos se han seleccionado cuatro materias representativas: la gestión de las aguas transfronterizas; la sanidad; la enseñanza; y la ganadería y la alimentación. Como podrá verse, la cooperación implica en ocasiones la creación de nuevos equipamientos (figura 2), mientras que en otras la adaptación de equipamientos o servicios ya existentes.

\section{Gestión del agua: la cooperación como mecanismo de resolución de conflictos}

El Tratado de los Pirineos convirtió en transfronterizos varios cursos fluviales, fuentes e infraestructuras hídricas de la cuenca hidrográfica del Ebro, incluido el río Segre y su principal afluente, el Querol. Desde entonces el control de las aguas ha sido objeto de importantes disputas, como en el caso de la Sèquia de Puigcerdà (del siglo XIV), que capta agua del Querol en territorio francés. Su partición y los cambios de uso producidos a lo largo del siglo XVIII (crisis de la molinería urbana y desarrollo de la agricultura y la ganadería comercial) provocaron conflictos con cierta periodicidad alrededor del uso del agua (Sahlins, 1991; Kirchner et al. 2002; Piguillem 2007). Con el Tratado de Límites de 1866 se pretendió poner fin a los litigios: en él se confirman los derechos y propiedad de Puigcerdà sobre el canal y sus márgenes; se garantiza el uso del agua para cada una de las partes, la española y la francesa, por períodos de 12 horas al día; y se crea una Comisión Internacional de Administración.

A pesar de las disposiciones del acuerdo, la competencia por el agua se ha mantenido hasta la fecha, motivada por los cambios en los usos durante el siglo XX (producción energética, aumento del consumo doméstico y desarrollo del turismo), junto con episodios de sequía, contaminación y descenso de la calidad, o por falta de mantenimiento. Por poner solo algunos acontecimientos recientes, en 1994 se produjo un conflicto debido a las obras de mantenimiento realizadas en suelo francés sin comunicación previa a las autoridades; en 1998 por la edificación en sus márgenes por parte de franceses; o en 2008 por la cantidad de agua captada durante la sequía de 2006-08, unido a las malas relaciones personales entre los alcaldes de Puigcerdà y Latour-de-Carol. En otras ocasiones, el conflicto no ha sido por el agua, sino que se ha usado como estrategia reivindicativa. Sirva de ejemplo la obstrucción del canal en 1986 por parte de Latour-de-Carol, Enveitg, Porta y Porté-Puymorens para presionar al gobierno español para que abriera el camino internacional de la Vinyola, cerrado desde la Guerra Civil y la Segunda Guerra Mundial.

Merece una referencia especial el conflicto por el aprovechamiento hidroeléctrico del lago Lanoux, situado en la parte alta del río Querol. Las disputas se iniciaron en 1917 con motivo del proyecto francés de embalse y recrecimiento del lago y el transvase de sus aguas al río Ariège (afluente del Garona). A pesar que dicho lago está situado en territorio francés y, por lo tanto, sus aguas son propiedad exclusiva de Francia, los agentes territoriales de la Cerdanya y el gobierno español entendían que su transvase constituía un incumplimiento de las disposiciones del Tratado de Límites de 1866 sobre el canal de Puigcerdà. Después de años de negociaciones infructuosas, proyectos alternativos y boicots, en 1956 se sometió la cuestión a arbitraje internacional. El tribunal, presidido por el rey de Suecia, Gustaf VI Adolf, dictaminó que el proyecto no contravenía dicho Tratado. A partir de este laudo se rubricó en 
1958 el Acuerdo hispano-francés sobre el aprovechamiento de las aguas del lago Lanoux (modificado en 1970), por el que Francia puede transvasar las aguas al Ariège a cambio de asegurar un caudal mínimo para al río Querol con agua del Ariège, captada en su parte alta, en el límite fronterizo con el Pas de la Casa (Andorra).

En varias ocasiones la resolución de estos y otros casos se ha realizado mediante la CIP, aunque la respuesta de los Estados no ha sido siempre la más adecuada. Por el contrario, la cooperación transfronteriza aparece como uno de los principales mecanismos de acción regional y local para su conciliación, que persigue dos grandes objetivos. Primero, resolver y evitar las disputas que, debido al crecimiento demográfico y turístico y, por lo tanto, de la demanda de agua, surgen periódicamente por su calidad, las captaciones (legales e ilegales) o las obras de mantenimiento. Segundo, implantar una gestión compartida sobre la base de unos principios ambientales y de sostenibilidad, de acuerdo al Convenio de Helsinki (1992), la Directiva marco del agua de la UE (2000) y el Acuerdo de Toulouse (2006).

Los primeros contactos se establecieron en los años 1970 con la propuesta y estudio de la CIP para la construcción de una depuradora para Puigcerdà, Llívia y Bourg-Madame, aunque la falta de voluntad impidió su materialización. Sin embargo, la creciente presión urbana y turística de los 80 hacía más urgente el saneamiento de las aguas residuales, y en 1989, en el marco de la AMC, se acordó el tratamiento de las aguas procedentes de las poblaciones del curso alto del Segre y el Querol (incluidas las del Pas de la Casa que, en virtud del Acuerdo del lago Lanoux, se transvasaban a dicho río). La propuesta se trasladó entonces a las autoridades regionales (Generalitat de Catalunya y Conseil Régional de LanguedocRoussillon) y a las administraciones hidrológicas (la Junta de Sanejament de Catalunya -la actual Agència Catalana de l'Aigua- y la Agence de l'Eau Rhône-Méditerrranée-Corse) para que dieran su apoyo y evaluaran la necesidad de una depuradora y/o una potabilizadora. El consiguiente estudio contó con financiación del programa INTERREG I. Poco después, en 1994, se iniciaba la construcción de la Estación Depuradora de Aguas Residuales (EDAR) de Puigcerdà, situada al lado del río Segre poco después de cruzar la frontera, que entró en funcionamiento al año siguiente; la planta potabilizadora, por otra parte, se construyó en 1996 y se situó también en Puigcerdà, al lado de la Sèquia antes de desembocar en el estanquedepósito de esta ciudad. El emplazamiento de la depuradora no estuvo exento de críticas; las autoridades locales francesas cuestionaban que se hubiera construido en la orilla izquierda del río, cuando Puigcerdà está en la derecha, justo en unos terrenos propiedad de un pariente del alcalde. La operación se completó con la conexión a la depuradora de los colectores de Angoustrine-Villeneuve-des-Escaldes, Bourg-Madame, Dorres y Ur, que se hizo efectiva en 1996 con una aportación de INTERREG II; posteriormente el convenio se amplió a otras poblaciones $^{8}$.

Como contrapartida la Generalitat de Catalunya exigió al gobierno francés el saneamiento del río Querol y que presionara al gobierno de Andorra para que depurara las aguas del Pas de la Casa. Este último accedió y en el Plan de saneamiento de las aguas de Andorra (1996) se incluyó la construcción de una depuradora y un colector en dicha localidad, en

8 Actualmente están conectadas las redes de las siguientes poblaciones: Puigcerdà (Puigcerdà, Age y Vilallobent), Llívia (Llívia y Gorguja), en España; Angoustrine-Villeneuve-des-Escaldes, Bourg-Madame (Bourg-Madame, Caldagas y Onces), Dorres, Err, Estavar (Estavar y Bajande), Llo, Saillagouse (Saillagouse, Ro y Vedrignans), Sainte-Léocadie y Ur, en Francia. 
funcionamiento desde 1998. Las autoridades centrales francesas, en cambio, sólo realizaron algunas intervenciones puntuales. Por el contrario, a instancias del Syndicat Intercommunal à Vocation Multiple (SIVOM) de la vallée du Carol y el Ayuntamiento de Puigcerdà, se realizó en 2003-2006 el proyecto INTERREG III «Gestion concertée de la rivière de Carol», centrado en la descontaminación del río y la depuración de las aguas residuales. El principal resultado fue la depuradora de Latour-de-Carol-Enveitg, situada unos metros antes de cruzar la frontera, e inaugurada en 2009. Paralelamente, apoyándose en las generalmente buenas relaciones personales, los ayuntamientos de Puigcerdà, Latour-de-Carol y Enveitg llegaron a otros acuerdos: sobre los vertidos de aguas residuales domésticas en el canal de Puigcerdà en territorio francés (1997), las construcciones ilegales en los terrenos adyacentes al canal (1998) o el soterramiento parcial del canal para agua destinada a consumo humano (2002).

Con el objeto de intensificar la cooperación, en 1999 el Consell Comarcal de la Cerdanya y la Charte Intercommunale de Cerdagne asentaron las bases para un «contrat de rivière»" transfronterizo para el Segre. Este incluye la gestión integral del curso, haciendo hincapié en la protección y valorización de los medios acuáticos y ribereños, las inundaciones y la contaminación. En su redacción participaron una amplia representación de los agentes territoriales implicados: los gobiernos locales y regionales (la Communauté de communes Pyrénées Cerdagne, el Conseil Général des Pyrénées Orientales, el gobierno de Andorra y los consejos comarcales de Cerdanya y Alt Urgell), las administraciones hidrográficas (la Agence de l'Eau Rhône-Méditerrranée-Corse, la Agència Catalana de l'Aigua y la Confederación Hidrológica del Ebro), además de otras entidades (la Fédération de Pêche, el Conseil Supérieur de la Pêche, el Parc Naturel Régional des Pyrénées Catalanes...). A pesar de las dificultades derivadas del gran número de agentes y las disputas que en aquel momento se daban (captaciones ilegales agrícolas, en el lado francés, y abastecimiento de nuevas urbanizaciones, en el español), los trabajos previos se realizaron con éxito. Finalmente el «Contrat de Rivière Transfrontalier du Sègre en Cerdagne» se puso en marcha en 2004 y ha contado con dos aportaciones INTERREG. Hasta el momento se ha actuado en la regulación de captaciones, la recuperación de áreas de bosque de ribera, la recuperación de elementos patrimoniales (molinos y fargas) para su aprovechamiento turístico y en acciones de educación ambiental, entre otros.

\section{Sanidad: de sucesos fortuitos a una cooperación pionera en Europa}

Aunque los flujos sanitarios transfronterizos eran prácticamente inexistentes (solamente algunos pacientes de la Cerdanya francesa acudían al hospital de Puigcerdà), el interés por la asistencia sanitaria transfronteriza, incluida la cooperación, se plasmó a fines de los años 1970 -con un estudio elaborado en 1978 por Joaquim Casanovas, médico de Toulouse- y a lo largo de los 1980. Se trataba principalmente que la población de la Alta Cerdanya y Capcir pudiera acudir al hospital de Puigcerdà, que se haya a $1 \mathrm{Km}$ de la frontera, en lugar de a los hospitales de referencia en Prades y Perpignan, a 60 y $100 \mathrm{Km}$.

9 El «contrat de rivière», contrato de río, es un instrumento legal francés consistente en un programa de acciones para la gestión y restauración de los medios fluviales a escala de las cuencas hidrográficas. 
A partir de la década de 1990 la cooperación se hará necesaria, debido a los efectos negativos para la Cerdanya derivados de la reestructuración de los sistemas sanitarios francés y catalán (español) (Mancebo, 1999a; Séchet y Keerle, 2009 y 2010). En el lado francés se inició en 1991 una importante reorganización de los servicios e instalaciones médicas, concentrándolos en unos pocos centros urbanos, lo que perjudicó gravemente las áreas rurales y de montaña, como la Alta Cerdanya y Capcir. En el lado español, el sistema sanitario catalán asignó inicialmente la Baixa Cerdanya al hospital de la Seu d’Urgell. En ambos casos, la suma de las poblaciones permitía justificar servicios e instalaciones en esta comarca.

Además de las dificultades técnicas, jurídicas o financieras, la cooperación ha debido superar, quizá como en ningún otro caso, las fuertes barreras psicológicas. Como indican Mancebo (1999a) y Moncusí (2005), la población francesa en general mostraba fuertes reticencias respecto a la calidad de los servicios y equipamientos sanitarios del lado español, fruto de la pervivencia de estereotipos sobre la sanidad en España (o sobre España en general). Incluso esta visión se vio agravada por las declaraciones de políticos como François Calvet, diputado por los Pyrénées-Orientales. En el cambio de esta percepción, y en el origen de las iniciativas actualmente en funcionamiento, fueron claves dos sucesos fortuitos acaecidos en 1996 y 2001 en la carretera N116, que une la Cerdanya con Prades y Perpignan. Un desprendimiento de tierras, el primero, y unas continuas nevadas, el segundo, provocaron su cierre durante varios días, lo que obligó a la población a dirigirse al hospital de Puigcerdà; entre otros datos, en 1996 quince mujeres residentes en Francia dieron a luz en el hospital español. A raíz de estos sucesos la población francesa pasó, como mínimo, a no desconfiar tanto de los servicios e instalaciones de Puigcerdà.

La primera propuesta firme de cooperar partió de la AMC y de la Eurorregión CatalunyaLanguedoc-Roussillon-Midi-Pyrénées. A instancia de aquellos organismos, los gobiernos de Catalunya y Languedoc-Roussillon firmaron en 1991 un convenio para la realización de un estudio sobre un posible hospital transfronterizo. Elaborado en 1994 por el Ordre des Médecins des Pyrénées-Orientales, evaluaba la posibilidad de asistir al conjunto de la Cerdanya en el existente (aunque deficiente) hospital de Puigcerdà, siguiendo el modelo utilizado en otros centros fronterizos de Europa (como en el de Menton, en la frontera franco-italiana), o en uno de nuevo.

Sobre la base de sus recomendaciones, y tras lo acaecido en 1996, se firmó aquel mismo año un primer convenio entre la Securité Sociale francesa y el Servei Català de Salut, que contó con el apoyo de la CTP y del Ordre des Médecins des Pyrénées-Orientales. De acuerdo con los reglamentos comunitarios (CEE) 1408/1971 y 574/1972, el convenio establecía la forma de pago de los gastos médicos de los pacientes de la Alta Cerdanya y Capcir en el hospital de Puigcerdà. Sin embargo, varias dificultades de orden técnico limitaron su funcionamiento (solamente se reintegraron los gastos de un $45 \%$ de los pacientes), que condujeron en 2006 a la firma de un nuevo convenio, de acuerdo al reglamento (CE) 883/2004, con el que el pago lo asume directamente la Securité Sociale o las compañías de seguros de los pacientes. Por otra parte, empujados por las nevadas de 2001, al año siguiente la Fundació Hospital de Puigcerdà, presidida por el acalde de la ciudad, Joan Carretero, médico de formación, y el Centre Hospitalier de Perpignan, dirigido por Joaquim Casanovas, firmaron un segundo convenio. En este se especifican los servicios sanitarios y se amplían las coberturas, y abarca tres ejes: asistencial (urgencias generales, obstetricia y hospitalización), profesional y técnica 
(intercambio de personal médico, formación e integración de la telemedicina) y económica (financiación sanitaria).

Durante las negociaciones de este último convenio se planteó el que ha sido el proyecto de mayor envergadura: el futuro Hospital de Cerdanya (HC), el primer centro hospitalario común de nueva construcción en Europa, y en sustitución del existente en Puigcerdà. La propuesta contó de inmediato con el apoyo entusiasta de algunos políticos de Pyrénées-Orientales, tales como Christian Bourquin, presidente del Conseil Général y, sorprendentemente, François Calvet. Progresivamente se sumaron los gobiernos regionales y locales de ambos lados (Conseil General des Pyrénées-Orientales, Conseil Régional de Languedoc-Roussillon, Generalitat de Catalunya, Consell Comarcal de la Cerdanya y Ayuntamiento de Puigcerdà) y las administraciones sanitarias (Agence Régionale de Santé Languedoc-Roussillon -ARSLR-, Departament de Salut, Servei Català de la Salut, Ministerio de Sanidad y Consumo, y Ministère de la Santé et des Sports) ${ }^{10}$. Después del estudio de viabilidad (jurídica, económica, compatibilidad de los sistemas sanitarios, etc.), cofinanciado por el programa INTERREG III, en 2003 se firmó el acuerdo de creación del nuevo hospital. Por el mismo se constituyó en 2005 su organismo gestor, la Fundación Hospital Transfronterizo de la Cerdanya, con base al Tratado de Bayona, y que en 2010 se sustituyó por la AECT Hospital de Cerdanya (AECT-HC), con base al Reglamento de las AECT. Este cambio no sólo refleja una mejora jurídica, sino que también simbólica en lo que se refiere a su denominación. El uso del concepto «transfronterizo» implicaba el reconocimiento de la frontera, que entraba en contradicción con el discurso de la unidad de la Cerdanya. En este sentido, a propuesta de varios alcaldes se optó por eliminar dicho concepto y referirse al hospital únicamente con el término «Cerdanya».

El HC responde a dos grandes objetivos, uno asistencial y otro de desarrollo económico. En primer lugar se trata de dotar a la Cerdanya de una estructura médica con capacidad de atender una población mínima de 30.000 habitantes e incluyendo la población turística, además de la posibilidad futura de asistir también la población de el Pas de la Casa, en Andorra. El segundo objetivo se refiere a la generación de efectos complementarios (fijación de la población, soporte al desarrollo turístico o refuerzo de la economía).

De estos objetivos se derivan varios retos, de los que cabe destacar dos. El primero, la construcción de un nuevo equipamiento. Inicialmente se apostó por Bourg-Madame o Ur, opciones que contaron con el apoyo de las respectivas alcaldías, aunque finalmente Puigcerdà se posicionó como mejor opción, cuyo Ayuntamiento cedió los terrenos donde se ubica (el Pla de Rigolisa, a unos $100 \mathrm{~m}$ de la frontera). Para esta ciudad se trata de consolidar y densificar urbanísticamente el sector norte del municipio, actualmente una zona agrícola fragmentada entre áreas residenciales de edificación aislada. El coste total es de $31 \mathrm{M} €$, financiado en un $60 \%$ por el programa Cooperación Territorial Europea (INTERREG IV), un $24 \%$ por la Generalitat de Catalunya y el restante $16 \%$ por el gobierno francés. Las obras de urbanización y construcción se han llevado a cabo entre 2009 y 2012, y se prevé su apertura a mediados de 2013. Desde 2003 se han producido varios retrasos debido a los ritmos de la administración urbanística (concurso de propuestas de edificación, aprobación del plan

10 En 2007 el Ministeri de Sanitat de Andorra se interesó por el proyecto. A fines de 2011 todavía no había prosperado su posible integración. 
urbanístico, adjudicación de las obras, etc.), además de problemas de orden técnico (como el contrato del servicio eléctrico francés, por ser más barato y regular su suministro, en suelo español) y de financiación.

Una mayor conciliación técnica, financiera y jurídica de los sistemas sanitarios francés y catalán constituye el segundo reto. El HC debe asistir a pacientes e integrar personal médico, administrativo y de servicios de ambos países. En este sentido, además de la mejora y ampliación de los aspectos ya concertados en los anteriores convenios, se han debido abordar cuestiones como el régimen laboral de los profesionales franceses, los impuestos sobre el trabajo, la formación y asistencia trilingüe (catalán, castellano y francés), los protocolos de actuación, el régimen de los neonatos y de los difuntos franceses, etc. Respecto a esta última, por ejemplo, para evitar que unos y otros deban pasar por trámites de extranjería, el HC ha adquirido un estatus similar al de consulado.

Por último, en un nuevo paso hacia una mayor intensidad e integración, en 2010 el Departament de Sanitat de la Generalitat de Catalunya y la ARSLR pusieron en marcha el «Proyecto Europeo de Sanidad de la Cerdanya», que tiene por objetivo integrar los servicios sanitarios especializados (urgencias, maternidad, geriatría, rehabilitación, nefrología, radiología, adictología, salud mental y pediatría). Dicho proyecto se sustenta en la creación de una red transfronteriza, que agrupa al HC y cuatro centros franceses, SRR les Escaldes (en Angoustrine), Maison de santé médicale Joseph Sauvy (en Err), MECSS les Touts Petits (en Bourg-Madame) y La Perle Cerdane (en Osséja). La red está abierta a que se sumen el resto de centros de sanidad privada y de turismo médico de la Alta Cerdanya y Capcir, como en el caso de la Clinique du Souffle La Solane (de Osséja), que en 1989 ya había propuesto un convenio de colaboración.

\section{Enseñanza: ¿una cooperación fracasada?}

Los proyectos desarrollados en materia de enseñanza pueden clasificarse en dos grupos. En primer lugar los que se sustentan en la construcción de nuevos centros educativos, en un espacio lo más cerca posible de la frontera, acompañado de la implantación de un modelo educativo homologable por los sistemas francés y catalán (español). En este sentido, la cooperación comparte muchas similitudes con el caso sanitario (cuanto a las dificultades derivadas de dos sistemas educativos y administrativos y a las estrategias movilizadas). Sin embargo, los resultados difieren bastante: los proyectos aquí incluidos no se han podido llevar a cabo por el momento. En segundo lugar, los proyectos entre centros ya existentes: actividades educativas conjuntas, elaboración de materiales pedagógicos, encuentros e intercambios, que han tenido un mayor éxito y continuidad.

Con relación al primer grupo, aunque no se trate de un caso de cooperación propiamente dicha, el primer proyecto se remonta a 1902, cuando se creó la «Escuela Franco-Española» de Puigcerdà (Moncusí, 2005). El centro estaba regido por un comité formado por 25 miembros, 13 del lado español y 12 del francés, la mayoría de Puigcerdà y Bourg-Madame, entre ellos sus alcaldes. En la base de su creación se hallan los contactos previos debidos al interés por el aprendizaje de la lengua francesa y por la obtención de títulos franceses.

A parte de aquella experiencia, la primera propuesta surgió en el marco de cooperación entre Llívia y Estavar. A mediados de los años 90 los equipos directivos de las escuelas de 
ambos municipios impulsaron una escuela primaria transfronteriza, aunque sin éxito por problemas administrativos y falta de apoyo político. Posteriormente, en el curso 2000-01, la misma propuesta fue acogida por las autoridades locales. Este segundo proyecto preveía el cierre de las escuelas de cada uno de los municipios y la construcción de un nuevo centro en una ubicación simbólica (en la misma línea fronteriza), y se acompañaba de la elaboración de un proyecto educativo común franco-español que permitiera unificar alumnado y profesorado. La propuesta no avanzó por las incompatibilidades entre ambos sistemas educativos, el rechazo por parte de padres y madres y de la comunidad educativa de ambos lados, especialmente de Llívia, y por una ubicación problemática (lejanía a los núcleos de población y otros equipamientos, propiedad del suelo y sospechas de intenciones especulativas).

Paralelamente en 2001 el IEC propuso la creación de un centro transfronterizo de educación secundaria post-obligatoria («Centre Pilot d'Ensenyament de Grau Mig de la Cerdanya»), que se ubicaría en Puigcerdà, en las instalaciones del instituto IES Pere Borell. Se basaba en la experiencia, con resultados satisfactorios, de otros centros en Europa, especialmente en las fronteras de Alemania con Países Bajos y Francia. La solicitud se hizo al Departament d'Educació de la Generalitat de Catalunya, al Ministère de l'Education del gobierno de Francia y a la UE, y contó con el apoyo (nominal) de varios gobiernos locales, instituciones, centros educativos de primaria y secundaria, y partidos políticos de ambos lados. Igualmente preveía que el título de secundaria fuera homologable y que las lenguas de enseñanza fueran el catalán, el francés y el castellano. Después de la negativa, el IES Pere Borell optó por un fórmula más sencilla, impartir también los estudios de Baccalaureat (Secondaire terminale) del sistema francés, de acuerdo a la normativa de centros docentes extranjeros en España. Su puesta en marcha estaba prevista para el curso 2011-12, pero se pospuso por falta de matriculaciones, tanto de estudiantes de la Alta como de la Baixa Cerdanya.

En 2007, por último, los alcaldes de Puigcerdà, Joan Planella, y de Bourg-Madame, Jean-Jacques Fortuny, apostaron también por intensificar la integración transfronteriza en el ámbito educativo. Inicialmente se apostó por la construcción de una guardería, en Puigcerdà, pero poco después se descartó. Por el contrario, en 2009, se acordó la construcción de una nueva escuela de primaria, situada en término de Bourg-Madame, en la que se impartiría un modelo educativo compartido y homologable. En 2011 no se había pasado de los contactos con el Departament d'Educació, el Ministère de l'Éducation nationale y la Mission Opérationnelle Transfrontalière.

En el segundo grupo se incluyen una amplia variedad de actividades educativas, en las que participan profesorado y alumnado de ambos lados. Desde los intercambios escolares entre dos municipios, hasta otras a escala comarcal y con una mayor repercusión fuera del ámbito escolar, como la Festa de l'Arbre, que se celebra cada primavera desde 1992, y los Jocs Olímpics dels Petits Muntanyencs / Jeux Olympiques des Petits Montagnards, cada invierno desde 2005. La Festa de l'Arbre, por exponer un solo caso, se implantó en varios municipios a lo largo de los años 80, hasta que en 1992, a iniciativa de las escuelas de Llívia y Estavar, se celebró la primera de carácter transfronterizo, siendo pionera en Europa. Se trata de una jornada lúdica de educación ambiental, cuyo eje central es una plantación de árboles, en la que participan todos los centros de primaria de la Cerdanya (entre 500 y 600 alumnos). Cuenta con la colaboración de varias entidades forestales y educativas y de las administraciones locales y regionales (ayuntamientos, Charte Intercommunale de Cerdagne, 
Consell Comarcal de Cerdanya, Parc Naturel Régional des Pyrénées Catalanes, etc.). Como la Diada de la Cerdanya, la Festa de l'Arbre se celebra alternativamente en una localidad de cada lado de la frontera o en dos localidades fronterizas colindantes (figura 2).

Por otra parte, la Festa de l'Arbre ha servido para incrementar y establecer otros proyectos de cooperación. Cabe destacar la confección de la maleta pedagógica «El Segre, un riu sense fronteres», la idea sobre la cual surgió durante la edición de 2003 (en Fontanals de Cerdanya) y que se presentó en la de 2009 (Osséja). El material pedagógico toma el río Segre como eje argumentativo para trabajar aspectos medioambientales, económicos, sociales, históricos y políticos. El proyecto fue elaborado por la Associació Segre, un equipo ad hoc integrado por técnicos y docentes de ambos lados, y que contó con el apoyo del proyecto «Contrat de Rivière Transfrontalier du Sègre en Cerdagne».

\section{Ganadería y alimentación: la cooperación como valor añadido}

El último ejemplo hace referencia al matadero transfronterizo de Ur, el segundo construido ex novo en Europa, después del de Sarreguemines (frontera franco-alemana). A diferencia de los anteriores ejemplos, este corresponde a un sector económico, el agrario, que desde los años 1970 está en clara regresión en la economía comarcal (pérdida de valor y rentabilidad). Las explotaciones que se mantienen deben constantemente reducir costes y/o introducir mejoras en el proceso de producción y comercialización. Con relación a este último aspecto, con la entrada en vigor en España y en Francia de nuevos reglamentos técnico-sanitarios aplicados a los mataderos, se aprovechó para reestructurar la dotación y capacidades de dichos equipamientos. En este sentido, en los años 1980 se cerraron los mataderos locales y fueron sustituidos por dos de carácter supramunicipal, los de Puigcerdà y Bourg-madame (situados a 3Km el uno del otro); únicamente se mantuvo el de Bellver, por su especialización en animales de caza. El objetivo era incrementar la capacidad de sacrificio, la reducción de costes y la comercialización de la carne en circuito corto. Sin embargo la reestructuración no dio respuesta a la totalidad de las necesidades estratégicas del sector. Por ejemplo, actualmente alrededor del $95 \%$ de las reses de la Baixa Cerdanya son sacrificadas fuera de la comarca, en equipamientos más adecuados (en la Seu d'Urgell, Vic y Girona); de forma similar ocurre en el lado francés, que son transportadas a Perpignan, Narbonne o Lavelanet. A excepción de la Seu d'Urgell, el resto se encuentra a una distancia superior a los $100 \mathrm{Km}$ y a 1 h $45 \mathrm{~m}$ de viaje.

En 2001 se planteó el estado de los mataderos, aprovechando la obligación de adecuarlos a la normativa europea de seguridad alimentaria en productos de origen animal (reglamentos (CE) 853/2004 y 854/2004). Se barajaron las posibilidades de reformar los tres existentes o construir uno nuevo de carácter transfronterizo que los reemplazara. Los órganos gestores, el Consell Comarcal de la Cerdanya y el Syndicat de l'Abattoir de Cerdagne-Capcir, optaron por esta segunda opción, que debería acompañarse de la creación de una región sanitaria transfronteriza. El proyecto se presentó en 2002, durante la Diada de la Cerdanya (en Eyne), con el que se espera un menor coste y una mayor rentabilidad económica, asegurar la continuidad e incrementar el sector ganadero (ovino, bovino y porcino), el volumen de producción y su área de mercado, y desarrollar un sector cárnico de calidad y con valor añadido (calidad del producto, calidad genética, seguridad alimentaria y ganadería ecológica). 
Con un retraso considerable respecto a la previsión inicial, no se dispuso del estudio de viabilidad (técnica, sanitaria, económica y jurídica) hasta 2006. Dicho estudio se financió con fondos del programa INTERREG III, del Conseil Général des Pyrénées-Orientales y del Conseil Régional de Languedoc-Roussillon, además del Consell Comarcal de la Cerdanya y del Syndicat de l'Abattoir de Cerdagne-Capcir. Para su realización se contó con la colaboración activa de los ganaderos y carniceros de ambos lados de la frontera, que condicionaron su éxito a la puesta en marcha de servicios complementarios (transformación, logística, etc.). Asimismo, de entre las diferentes propuestas, este colectivo optó por ubicarlo en Ur, cerca de la frontera con el enclave de Llívia.

Ambos órganos gestores procedieron a la compra del terreno, la redacción del proyecto arquitectónico y técnico, y la licitación y adjudicación del contrato de obras. Inicialmente se previó que la construcción empezara en 2006, aunque el proceso administrativo y la búsqueda de financiación demoraron su comienzo hasta mediados de 2011. El coste presupuestado es de 3,1 M€, de los que 1,9 M€ proceden del programa INTERREG IV, y el resto de la Generalitat de Catalunya, la Communauté de Communes Pyrénées-Cerdagne, el Conseil Général des Pyrénées-Orientales, el Conseil Régional de Languedoc-Roussillon y el gobierno francés. El retraso en los pagos por parte de la Generalitat, imbuida en una crisis financiera, provocó la paralización de las obras a mediados de 2012, con lo que no sé prevé su puesta en marcha hasta 2013. Una vez terminado, la «gestión institucional» pasará a la AECT Pirineus-Cerdanya, mientras que la gestión productiva y empresarial estará a cargo de la Association de Gestion de l'Abattoir Transfrontalier de Cerdagne en Pyrénées Catalanes, entidad formada en 2009 que reúne los ganaderos y carniceros de ambos lados de la frontera.

Por último, en la misma línea que la realización del matadero transfronterizo se sitúa la proposición de etiquetas de calidad transfronterizas para productos alimentarios. Los ganaderos de ambos lados han trabajado en los diez últimos años para la creación de una Indicación Geográfica Protegida para productos cárnicos (IGP Rosée et vedell des Pyrénées catalanes) y la extensión a la Alta Cerdanya y Capcir de dos Denominaciones de Origen Protegidas para lácteos (DOP Formatge y DOP Mantega de l'Alt Urgell i la Cerdanya). En 2011 todavía no se habían conseguido por las dificultades técnicas y administrativas a escala regional, estatal y europea. Sin embargo, esto no es impedimento para que desde 2008 la Cooperative Cimlait, que agrupa la mayor parte de explotaciones lecheras de la Alta Cerdanya y Capcir, venda toda su producción a la Cooperativa del Cadí, que agrupa las de la Baixa Cerdanya y Alt Urgell.

\section{CONCLUSIONES}

La construcción de la Cerdanya como región transfronteriza se produce, como hemos podido ver, mediante iniciativas y proyectos de cooperación transfronteriza, en gran medida vinculada a la especialización territorial (los servicios). En este proceso se han movilizado varios agentes territoriales de ambos lados de la frontera (administraciones locales, políticos, entidades civiles y agentes privados) y en los que se genera y refuerza el discurso de una unidad geográfica, económica y cultural y, consiguientemente, la idea de compartir un territorio, unas dinámicas y una identidad. Como muestran otras investigaciones, las interrelaciones económicas, demográficas o sociales -que no han sido objeto de este artículo- también con- 
tribuyen en su construcción. A pesar de lo dicho, la cooperación transfronteriza no solo sirve para la construcción regional, sino que también es una estrategia de desarrollo, en este caso de un área de frontera, rural y de montaña.

La distribución territorial del proceso de construcción regional presenta dos espacios, de densidad cooperativa diferente. El primero, un espacio ideal, donde se construye el discurso sobre la unidad de la Cerdanya, la superación de la frontera hispano-francesa y se promueve la cooperación transfronteriza como medio para obtenerlo. Este espacio corresponde, con algunas excepciones que aquí no se han analizado, a la totalidad de la Cerdanya, pero con un claro liderazgo de los agentes de la Baixa Cerdanya. El segundo, un espacio más reducido y superpuesto al anterior, donde además se implementa la mayor parte de los proyectos de cooperación. Este se limita a los municipios estrictamente fronterizos, donde la cooperación se justifica en un sentido más funcional que retórico. Los municipios con mayor participación corresponden al área central de la Cerdanya: Puigcerdà y Llívia, por el lado español, y Bourg-Madame, Ur, Estavar, Saillagouse, Osséja, Enveitg y Latour-de-Carol, por el francés. En este espacio predominan cuantitativamente los agentes de la Alta Cerdanya, pero el liderazgo es a menudo ejercido desde Puigcerdà.

Esta última apreciación nos lleva a señalar varias divergencias entre retórica y práctica. Primera, la «Cerdanya unida» está presente en la justificación y en los resultados deseados y obtenidos de la cooperación, pero la participación de los agentes de ambos lodos de la frontera no es igualitaria. Desde el lado francés se percibe un excesivo dominio y centralización de los proyectos de cooperación por parte del lado español. Si bien el peso demográfico de Puigcerdà, su dotación de servicios, condición fronteriza y estar travesada por cursos fluviales e infraestructuras hidráulicas y de transporte en parte lo explican, existen otros motivos para el recelo. Así, por ejemplo, el proyecto y ejecución de la EDAR de Puigcerdà fueron únicamente liderados por la Baixa Cerdanya, mientras la Alta Cerdanya sólo se limitó a pagar la parte que le correspondía. Sin embargo, en los últimos años esta relación desigual está cambiando: la gestión de los proyectos del hospital i del matadero ha sido más conjunta. Una segunda divergencia palpable es el uso en ocasiones de la «frontera» para obtener mayores ventajas en un lado que en el otro, para presionar y forzar decisiones o para justificar la separación. Puede hacerse referencia, en este sentido, a la amenaza de no autorizar la conexión de los colectores franceses a la estación depuradora de Puigcerdà si no se cumplía con el Acuerdo del lago Lanoux, o los prejuicios del lado francés sobre los servicios e instalaciones sanitarias de Puigcerdà.

Paralelamente, y en tercer lugar, la voluntad de una integración institucional se muestra y refuerza con la celebración de actos (la Diada de la Cerdanya), foros permanentes (el Encuentro anual de alcaldes) y la creación de organismos transfronterizos (la Asociación de Municipios de la Cerdanya, la AECT Pirineos-Cerdanya o el Consorcio transfronterizo Puigcerdà-Bourg-Madame). A pesar de ello, su utilidad práctica es menor a la deseada. Cuarta, resulta sorprendente la ausencia de una mayor coordinación y reflexión global e integral a escala comarcal, evaluación de la coherencia de los proyectos o puesta en común de los resultados y aprendizajes. La falta de coordinación también resulta patente en un espacio transfronterizo mayor, aunque a este respecto los organismos de cooperación de escala regional (el Eurodistrito del Espacio Catalán Transfronterizo, la Euroregión Pirienos-Mediterráneo y la Comunidad de Trabajo de los Pirineos), asumen en menor o mayor grado esta función. 
Por otra parte, los ejemplos analizados (gestión del agua, sanidad, educación escolar y ganadería y alimentación) ofrecen una perspectiva temática complementaria a la territorial. Tres son las principales características, en relación con las motivaciones, el objeto y la evaluación de la cooperación. En cuanto a las motivaciones, a menudo se ha reducido a un simple interés pecuniario, de obtención de fondos europeos de los programas INTERREG. Según esta argumentación, de no ser por la posible financiación exterior, no se habrían llevado a cabo muchos de los proyectos. Sin embargo, los casos estudiados muestran que también existen otras motivaciones, siendo en ocasiones más relevantes. Pueden nombrarse la resolución i/o evitación de conflictos fronterizos (en la cooperación en gestión del agua), la agregación de valor añadido en sectores económicos en crisis y con necesidad de innovaciones y nuevos mercados (cooperación en ganadería y alimentación), o la formación de cuencas de población suficientes para la planificación de servicios, equipamientos o infraestructuras de escala supramunicipal (cooperación en sanidad y en enseñanza).

La segunda característica hace referencia al objeto de cooperación (el uso y gestión compartida de servicios, actividades, equipamientos o infraestructuras), cuya implantación sigue dos estrategias complementarias. Por un lado, la cooperación respecto a los servicios, equipamientos... ya existentes, que son redimensionados en el marco de un nuevo espacio transfronterizo. Esta estrategia es representada, entre otros, por los convenios de 1996 y 2001 para la atención sanitaria de la población de la Alta Cerdanya y Capcir en el hospital de Puigcerdà; las actividades escolares conjuntas, como la Festa de l'Arbre; la gestión compartida del río Segre; o la urbanización de espacios interurbanos entre Puigcerdà y Bourg-Madame y entre Llívia y Estavar. Por otro lado, respecto a aquellos de nueva creación, que son dimensionados desde su planificación en el marco del espacio transfronterizo (y que en ocasiones vienen a sustituir los obsoletos). En este caso, se trata de experiencias como la construcción del matadero transfronterizo de Ur, del Hospital de Cerdanya, de la EDAR de Puigcerdà o los proyectos infructuosos de creación de centros educativos. Esta segunda estrategia, a diferencia de la anterior, ha recibido mayores críticas, sobre todo cuanto a las cuestiones urbanísticas: la titularidad del suelo, el desarrollo urbanístico de la zona y la percepción de presiones especulativas, sumado a un contex to donde el sector inmobiliario y de la construcción constituye uno de los pilares económicos.

En tercer lugar, la evaluación de los procesos y los resultados presenta valoraciones distintas en cada caso, no generalizables al conjunto. La cooperación en sanidad (construcción y puesta en marcha del Hospital de Cerdanya), por ejemplo, puede calificarse de éxito, si bien es cierto que también se trata de una cooperación tardía y en algunos aspectos fruto de sucesos fortuitos, junto con la existencia de fuertes reticencias. Asimismo, la cooperación en enseñanza puede haber fracasado en aquellos casos que implican la construcción y puesta en práctica de centros educativos compartidos, pero han supuesto un éxito los intercambios y fiestas escolares y la elaboración de materiales pedagógicos. En todo caso, las razones del éxito o fracaso pueden ser varias, de las que pueden destacarse las siguientes: desavenencias entre los agentes, ya sea entre los dos lados o de los mismos; ritmos administrativos, políticos, técnicos o financieros lentos o incompatibilidades, en contraposición a las expectativas creadas; o permanencia de las barreras (psicológicas, lingüísticas, legales, etc.), a pesar de la retórica de la unidad de la Cerdanya y de la integración europea. 
Poco a poco se ha avanzado en la integración de la Cerdanya mediante la cooperación transfronteriza, aunque ciertamente no tan rápido como algunos hubieran querido. Observada en perspectiva supone un éxito significativo, tanto en la Cerdanya como en la frontera hispanofrancesa. Hasta hace 30 años se trataba de un proceso prácticamente inconcebible. En este sentido, los debates en los años 1970 en torno al hospital y al matadero de Puigcerdà permiten ejemplificarlo. Ambos equipamientos necesitaban mejoras importantes, pero entre las diferentes soluciones nunca se pensó en contar con la Alta Cerdanya y Capcir, ya que no existía a nivel político y administrativo el marco de una Cerdanya unida. Sin duda, la frontera era un límite físico, legal y mental entre dos realidades territoriales diferenciadas (España y Francia). En todo caso, el éxito de la cooperación se refleja en el proceso de superación de estas tres dimensiones de la frontera. Este aspecto debe subrayarse por cuanto que a menudo se olvida y, por el contrario, se pone el énfasis en los aspectos técnicos, financieros, administrativos y jurídicos.

\section{BIBLIOGRAFÍA}

ARBAIZA, J.K. (2006): «Proyectos de cooperación transfronteriza en el País Vasco: objetivos y realidad», Lurralde, n 29, 143-177.

BARBA, M. y SERRA, S. (2007): «Propostes per a l'Hospital Transfronterer a Puigcerdà». Quaderns d'arquitectura i urbanisme, $\mathrm{n}^{\circ}$ 253, 154-159.

BERNAD, M. (1984): «Un organisme de coopération transfrontalière: la Communauté de Travail des Pyrénées». Annuaire français de droit international, vol. 30, 819-835.

BRUNET, M. (2008): «Frontera cerdana e identidades nacionales en el siglo XIX». Manuscrits: Revista d'Història Moderna, $\mathrm{n}^{\circ}$ 26, 121-131.

CASTAÑER, M.; FELIU, J.; GUTIÉRREZ, O. (2011): «Llibre blanc de l'Eurodistricte Català Transfronterer: creació de projecte i reestructuració territorial». Documents d'Anàlisi Geogràfica, nº 57, 2, 281-292.

CAPDEVILA, J. (2009): Historia del deslinde de la frontera hispano-francesa. Del tratado de los Pirineos (1659) a los tratados de Bayona (1856-1868). Madrid. Centro Nacional de Información Geográfica.

CORDERO, J.M. (1960): Fronteras hispánicas. Geografía e historia, diplomacia y administración. Madrid. Instituto de Estudios Políticos.

DORNEL, L. (2002): «La frontière (le voisin) et l'étranger. Les enjeux identitaires d'un conflit frontalier». Revue d'Histoire du XIXe Siècle, no 24, 111-124.

FERNÁNDEZ DE CASADEVANTE, C. (1989): La frontière franco-espagnole et les relations de voisinage. Bayona. Harriet.

- (1990): La cooperación transfronteriza en el Pirineo: su gestión por las comunidades autónomas. Oñati. Instituto Vasco de Administración Pública.

FERNÁNDEZ, N. y PERALTA, E. (1994): «El papel de la Comunidad de Trabajo de los Pirineos y su evolución en el contexto europeo de cooperación transfronteriza territorial». Revista de Instituciones Europeas, vol. 21, n 2, 499-528.

FORNIER, E. (1969): «Les passages frontaliers en Cerdagne et Haute-Ariège». Revue Géographique des Pyrénées et du Sud-Ouest, vol. 40, nº 3, 225-242.

HAMMAN, P. (2003). «La coopération intercommunale transfrontalière: vers une nouvelle gouvernance locale en Europe ?», Pyramides, nº 7, 183-202. 
HARGUINDÉGUY, J.B. (2007): La frontière en Europe, un territoire? : coopération transfrontalière franco-espagnole. París. Harmattan.

HARGUINDÉGUY, J.B y RODRÍGUEZ, P. (2010): «Gobernanza multi-nivel y política regional europea. La implementación de INTERREG III-A España-Francia». Revista de Estudios Regionales, $\mathrm{n}^{\circ}$ 88, 199-222.

HEREDERO, M.I. y OLMEDILLAS, B. (2009): «Las fronteras españolas en Europa: de INTERREG a la cooperación territorial europea». Investigaciones regionales, $\mathrm{n}^{\circ} 16,191-215$

HINFRAY, N. (2007). «Les processus de construction des territoires transfrontaliers en Europe: éléments d'analyse». Mosella, $\mathrm{n}^{\circ} 32$ (1-4), 79-95

JANÉ, Ò. (2006): Catalunya i França al segle XVII : identitats, contraidentitats $i$ ideologies a l'època moderna: 1640-1700. Catarroja. Afers.

JANÉ, Ò. (2009): La identitat de la frontera pirinenca : efectes socials i polítics al nord de Catalunya des de la creació de Montlluís, 1677-1698. Girona. Diputació de Girona.

KIRCHNER, H., OLIVER, J. y VELA, S. (2002): Aigua prohibida. Arqueologia hidràulica del feudalisme a la Cerdanya. El Canal Reial de Puigcerdà. Bellaterra. Universitat Autònoma de Barcelona.

LELOUP, F. (2010). «Le développement territorial et les systèmes complexes: proposition d'un cadre analytique». Revue d'Économie Régionale \& Urbaine, $\mathrm{n}^{\circ}$ 2010/4, 687-705

MANCEBO, F. (1999a): La Cerdagne et ses frontières: conflits et identités transfrontalières. Perpinyà. El Trabucaire.

MANCEBO, F (1999b): «Museus de Cerdanya: instrumentalisation d'une initiative transfrontalière de valorisation du patrimoine». Sud-Ouest Européen. Revue Géographique des Pyrénées et du Sud-Ouest, $\mathrm{n}^{\circ}$ 5, 75-82.

MANCEBO, F (2000): «En Cerdagne, des clivages qui relient, des unions qui divisent : réorganisations spatiales et actions transfrontalières en Cerdagne après l'ouverture des frontières». Revue de l'Economie Méridionale, vol 48, n 192, 441-460.

MAURY, C. y RICHARD, S. (2011): «La difficile gestion de l'eau en contexte transfrontalier: un exemple franco-espagnol». Journal of Urban Research, $\mathrm{n}^{\circ}$ 6. Disponible en http:// articulo.revues.org/1736.

MERCADAL, O. y INIESTA, M. (1999): «Museus de Cerdanya: un projecte transfronterer per a un territori comú», en Actes del $2 n$ Congrés Català de Museus Locals i Comarcals (Alcalde, G. et al., Eds.), Olot, Museu Comarcal de la Garrotxa, 69-76.

MISSION OPERATIONNELLE TRANSFRONTALIERE (MOT) y UNIVERSITAT DE GIRONA (UdG) (2008): Llibre blanc de l'Eurodistricte, per a un futur transfronterer. Barcelona / Perpignan. Generalitat de Catalunya / Conseil Régional des Pyrénées-Orientales.

MONCUSÍ, A. (2005): Fronteres, identitats nacionals i integració europea: el cas de la Cerdanya. Catarroja / València. Afers / Universitat de València.

MONCUSÍ, A. (2008): «Fronteres i evolucions locals: el cas de la Cerdanya».Miramanda, $n^{\circ} 3,58-66$.

MUÑOZ, X. (1995): Les polítiques europees de cooperació transfronterera. El context normatiu, institucional i de finançament als Pirineus Orientals. Vilassar de Mar. Oikos-Tau.

MURRAY, D.S. (2003) «L'évolution des frontières de l'état français et de l'identité culturelle basque : perspectives anthropologiques», Lapurdum, $\mathrm{n}^{\circ} 8,375-388$. 
OLIVERAS, X. (2012): «La cooperació transfronterera en la gestió de conques fluvials a la frontera franco-andorrano-espanyola». Estudis d'Història Agrària, nº 24, 233-249.

OLIVERAS, X., DURÀ, A. y PERKMANN, M. (2010): «Las regiones transfronterizas: balance de la regionalización de la cooperación transfronteriza en Europa (1958-2007)». Documents d'Anàlisi Geogràfica, nº 56.1, 21-40.

PERKMANN, M. (2003). «Cross-border regions in Europe. Significance and drivers of regional cross-border co-operation». European Urban and Regional Studies, $\mathrm{n}^{\circ} 10$ (2), 153-171.

PIGUILLEM, J.M. (2007): Estudi històric sobre el canal de Puigcerdà. Puigcerdà. Servei Municipal d'Aigües.

QUÍLEZ, E. (2009): La Cerdanya a la balitresca. La Seu d'Urgell. Salòria

SAHLINS, P. (1993) [1991]: Fronteres i identitats: la formació d'Espanya i França a la Cerdanya s. XVII-XIX. Vic. Eumo.

SÉCHET, R. y KEERLE, R. (2009): «Le projet d'hôpital commun transfrontalier de Puigcerdà: vers l'européinisation de la frontière en Cerdagne». Sud-ouest européen: revue géographique des Pyrénées et du Sud-Ouest, $\mathrm{n}^{\mathrm{0}}$ 28, 65-76.

SÉCHET, R. y KEERLE, R (2010): «Le projet d'hôpital commun transfrontalier de Cerdagne : des difficultés de la coopération transfrontalière en matière de santé dans un contexte pourtant favorable». Annales de geographie, $\mathrm{n}^{\circ} 675,536-558$.

SERMET, Jean (1983). La frontière hispano-française des Pyrénées et les conditions de sa délimitation. Pau: Amis du Livre Pyrénéen.

SPA, Miquel (2011): «Dos estats, dues vides. Cerdanya, la vall dels dos ritmes». Revista. Suplement setmanal de Regió 7, 5 de noviembre de 2011, p. 2-5.

TAMBOU, O. (2000): «El tractat de Baiona: un èxit relatiu per al desenvolupament de la cooperació transfronterera en l'àmbit de la frontera francoespanyola». Autonomies . Revista Catalana de Dret Públic, $\mathrm{n}^{\circ} 26,41-96$.

TRILLO, J.M. y LOIS, R. (2011). «La frontera como motivo de atracción: una breve mirada a las relaciones Galicia-Região Norte». Geopolítica(s), nº 2 (1), 109-134.

TULLA, A.F. (1977): «Les deux Cerdagnes. Exemple de transformations economiques asymetriques de part et d'autre de la frontiere des Pyrenees». Revue geographique des Pyrenees et du Sud-Ouest, $\mathrm{n}^{\circ}$ 48(4), 409-424.

- (1997): «La Cerdanya: dues realitats en un únic espai» en A l'entorn de la frontera (Domingo, J. y Mallart, L., Eds.). Vilassar de Mar, Oikos-Tau, 85-104.

L'Aixurit (Palau-de-Cerdagne, 1993-1997)

La Cerdaña (Puigcerdà, 1897-1906)

La Vanguardia (Barcelona, 1881-...)

Periòdic d'Andorra (Escaldes-Engordany, 1997-...)

Regió 7 (Manresa, 1978-...)

Rufaca (Puigcerdà, 1977-1994)

Institut d'Estadística de Catalunya: www.idescat.cat

Institut National de la Statistique et des Études Économiques: www.insee.fr 